\title{
Clear cell 'sugar' tumour of the lung
}

\author{
Luke Martin O'Brien (ㄷ, ${ }^{1}$ Rhona Thuillier, ${ }^{2}$ Michael Tolan, ${ }^{1}$ Aurelie Fabre ${ }^{2,3}$
}

'Department of Cardiothoracic Surgery, St Vincent's University Hospital, Dublin, Ireland ${ }^{2}$ Department of Histopathology, St Vincent's University Hospital, Dublin, Ireland

${ }^{3}$ School of Medicine, University College Dublin, Dublin, Ireland

\section{Correspondence to}

Dr Luke Martin O'Brien; luke.o-brien.1@ucdconnect.ie

Accepted 2 February 2021

\section{DESCRIPTION}

A 43-year-old woman was referred to our thoracic surgery department following multidisciplinary team (MDT) discussion for a concerning $7 \times 5 \mathrm{~mm}$ pulmonary nodule in the medial right upper lobe which was discovered incidentally on a CT thorax abdomen pelvis (figure 1) as part of surveillance for her previous cervical cancer. This woman has a history of squamous cell carcinoma of the cervix (stage IIB), which was diagnosed in 2012 and managed with chemoradiotherapy. Unfortunately, she had a number of complications secondary to radiotherapy including a colovesical fistula (2013), defunctioning loop ileostomy formation (2014), vesicovaginal fistula (2014) and recurrent urirnary tract infection (UTIs). In late 2014, she developed a $4 \mathrm{~cm}$ cutaneous squamous cell metastasis in her right flank which was surgically excised. Her other medical history includes lupus and hypothyroidism. She is a non-smoker. Following identification of the pulmonary nodule on CT TAP, she underwent PET CT. However, the subcentimetre nodule was too small to resolve with PET and remained indeterminant. No other concerning areas of uptake were identified. The differential diagnosis clinically was metastatic cervical carcinoma or a primary lung neoplasm. She subsequently underwent right video-assisted thoracoscopic surgery upper lobe wedge resection.

Macroscopic examination of the lung wedge revealed a circumscribed, firm, white nodule, measuring 7 $\mathrm{mm}$ in largest dimension, excised by $1 \mathrm{~mm}$ to the closest resection margin. Microscopic examination revealed the nodule to be a well-circumscribed tumour composed of nests of bland cells with clear and granular cytoplasm, set in a hyalinised stroma (figure 2).

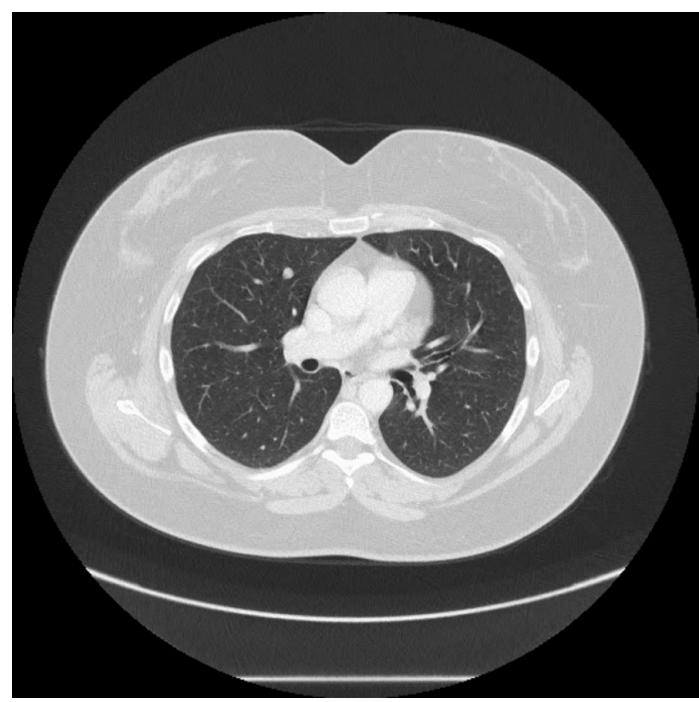

Figure 1 CT thorax abdomen pelvis—new $7 \times 5 \mathrm{~mm}$ nodule in medial right upper lobe.

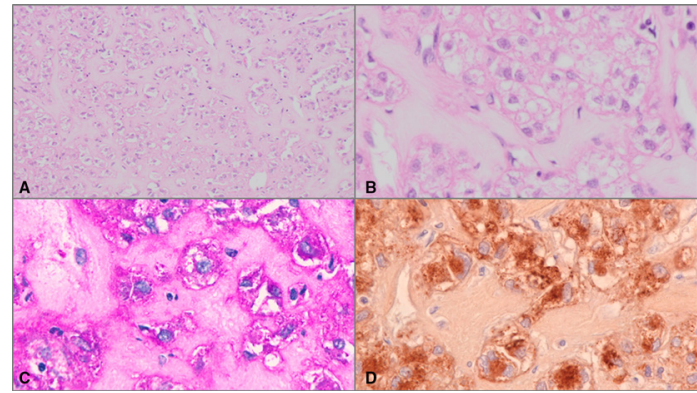

Figure 2 (A) nests of bland cells with clear and granular cytoplasm within a hyalinised stroma, H\&E stain $\times 100$ magnification, (B) H\&E stain $\times 400$ magnification, (C) positive cytoplasmic periodic acidSchiff staining of glycogen within tumour cells, $x 400$ magnification, (D) tumour cells showing positive HMB45 immunohistochemistry, x400 magnification.

Significant cytological atypia was not seen. Mitoses were not evident. Immunohistochemistry showed that the lesional cells stained positively for HMB45, with focal positivity for melan A. The cytoplasmic granules stained positively with periodic acid-Schiff and negatively with periodic acid-Schiff diastase, confirming the presence of glycogen. Immunohistochemistry for SOX10, S100, desmin, synaptophysin, PAX8, ERG, oestrogen receptor, AE1/3, p63, CK5/6, TTF-1 and napsin A were negative. Features of metastatic squamous cell carcinoma were not seen. Following histopathological analysis (figure 2), the diagnosis of clear cell 'sugar' tumour (CCST) of the lung was made that showed no malignant features. As this was a benign pulmonary lesion, this woman's follow-up will be guided by her primary cervical cancer.

CCST has been recently recognised to belong to the perivascular epithelioid cell tumour (PEComa) family of tumours. ${ }^{1}$ These are rare mesenchymal neoplasms that appear to arise from perivascular epithelioid cells and have morphological, immunophenotypic and ultrastructural similarities. PEComas usually have a combined myogenic and melanocytic immunophenotype. They occur more commonly in women. PEComas include specific entities such as CCST of the lung, angiomyolipoma and pulmonary lymphangioleiomyomatosis, and can occur as PEComas in the viscera, soft tissue and skin. Most PEComas are sporadic, but an association with tuberous sclerosis complex has been shown in angiomyolipoma, lymphangioleiomyomatosis and very rarely CCST. ${ }^{1}$

CCST is a rare tumour arising in the lung. It was first described by Liebow and Castleman. ${ }^{2}$ CCST usually arise in the periphery of the lung, are often incidentally detected, and can measure up to $7 \mathrm{~cm}$ in size. They are composed of nests of uniform cells that have both clear and granular cytoplasm, well-defined cell borders 
and lack cytonuclear atypia and mitoses. ${ }^{1}$ The cytoplasmic granules are composed of glycogen, which stain positively with periodic acid Schiff. Dilated vascular spaces surrounded by walled vessels are prominent. Necrosis and haemorrhage are not seen. Some cells may have a spindled morphology and stain positively with actin. Tumour cells should stain positively with melanocytic markers such as MiTF, Melan A and HMB-45 and negatively with epithelial markers. ${ }^{3}$ S100 may be positive.

The pathological differential diagnoses include pulmonary metastasis of clear cell renal carcinoma, primary clear cell carcinoma of the lung, paraganglioma, primary intrapulmonary meningothelial neoplasm and malignant melanoma. ${ }^{4}$

Most clear cell 'sugar' tumours of the lung behave in a benign fashion but eight potentially malignant or malignant cases have been reported to date in the literature. ${ }^{4}$ Zhao et al proposed criteria for malignancy as follows:

Primary diagnostic criteria: prominent coagulative tumour necrosis, infiltration of adjacent pleura or viscera, distant metastasis of homology, pathological mitotic figure $\geq 1 / 50 \mathrm{HP}$ (high power).

\section{Learning points}

- Clear cell 'sugar' tumour of the lung is a rare benign lung tumour usually arising in the periphery of the lung and often detected incidentally.

- The tumour cells should stain positively with periodic acid-Schiff due to cytoplasmic glycogen granules and also stain positively with HMB45/Melan A demonstrating the melanocytic immunophenotype.

- Criteria for malignancy seen in rare cases include tumour size $\geq 3 \mathrm{~cm}$ spotty or coagulative tumour necrosis, high mitotic index $\geq 5 \%$ with atypical mitoses, multinucleated tumour giant cells $\geq 5 / 50 \mathrm{HP}$, marked hypercellularity, nuclear atypia and pleomorphism, numerous intranuclear pseudoinclusions infiltration of adjacent pleura or viscera and distant metastasis.
Secondary diagnostic criteria: tumour size $\geq 3 \mathrm{~cm}$, spotty necrosis, high mitotic index $\geq 5 \%$, multinucleated tumour giant cells $\geq 5 / 50 \mathrm{HP}$, marked hypercellularity, nuclear atypia and pleomorphism, numerous intranuclear pseudoinclusions. ${ }^{4}$

The criteria for the diagnosis of malignant lung PEComa that they recommend are that the tumour meets 1-2 major diagnostic criteria and/or one more secondary diagnostic criterion. If the tumour satisfies only two or more secondary diagnostic criteria, they suggest the diagnosis of lung PEComa with malignant potential. ${ }^{4}$

Using these diagnostic criteria, this case of CCST would be classified as benign. However, due to the rarity of these lesions, it is difficult to be certain at present of their clinical behaviour. ${ }^{5}$

\section{Twitter Luke Martin O'Brien @lukeob13}

Acknowledgements Thank you to the patient for kindly allowing us to submit the case.

Contributors LMO - manuscript preparation \& junior doctor caring for patient. RT - manuscript preparation \& registrar reading histopathology slides. MT - manuscript editing \& consultant caring for patient. AF - manuscript preparation \& consultant reading histopathology slides.

Funding The authors have not declared a specific grant for this research from any funding agency in the public, commercial or not-for-profit sectors.

Competing interests None declared.

Patient consent for publication Obtained.

Provenance and peer review Not commissioned; externally peer reviewed.

\section{ORCID iD}

Luke Martin O'Brien http://orcid.org/0000-0003-1568-3951

\section{REFERENCES}

1 Hornick JL, Fletcher CDM. PEComa: what do we know so far? Histopathology 2006:48:75-82.

2 Liebow AA, Castleman B. Benign clear cell ("sugar") tumors of the lung. Yale J Biol Med 1971:43:213-22.

3 Gaffey MJ, Mills SE, Zarbo RJ, et al. Clear cell tumor of the lung. immunohistochemical and ultrastructural evidence of melanogenesis. Am J Surg Pathol 1991;15:644-53.

4 Zhao J, Teng H, Zhao R, et al. Malignant perivascular epithelioid cell tumor of the lung synchronous with a primary adenocarcinoma: one case report and review of the literature. BMC Cancer 2019:19:235.

5 Folpe AL, Kwiatkowski DJ. Perivascular epithelioid cell neoplasms: pathology and pathogenesis. Hum Pathol 2010;41:1-15.

Copyright 2021 BMJ Publishing Group. All rights reserved. For permission to reuse any of this content visit

https://www.bmj.com/company/products-services/rights-and-licensing/permissions/

BMJ Case Report Fellows may re-use this article for personal use and teaching without any further permission.

Become a Fellow of BMJ Case Reports today and you can:

- Submit as many cases as you like

- Enjoy fast sympathetic peer review and rapid publication of accepted articles

- Access all the published articles

- Re-use any of the published material for personal use and teaching without further permission

Customer Service

If you have any further queries about your subscription, please contact our customer services team on +44 (0) 2071111105 or via email at support@bmj.com.

Visit casereports.bmj.com for more articles like this and to become a Fellow 